\title{
Hypothermic machine perfusion increases A20 expression which protects renal cells against ischemia/reperfusion injury by suppressing inflammation, apoptosis and necroptosis
}

\author{
ZIXUAN YANG $^{1}$, ZIBIAO ZHONG $^{1}$, MINGXIA LI $^{1}$, YAN XIONG $^{1}$, \\ YANFENG WANG ${ }^{1}$, GUIZHU PENG ${ }^{1}$ and QIFA YE ${ }^{1,2}$ \\ ${ }^{1}$ Zhongnan Hospital of Wuhan University, Institute of Hepatobiliary Diseases of Wuhan University, Transplant Center \\ of Wuhan University, Hubei Key Laboratory of Medical Technology on Transplantation, Wuhan, Hubei 430071; \\ ${ }^{2}$ The Third Xiangya Hospital of Central South University, Research Center of National Health Ministry \\ on Transplantation Medicine Engineering and Technology, Changsha, Hunan 410013, P.R. China
}

Received November 20, 2015; Accepted April 21, 2016

DOI: $10.3892 / \mathrm{ijmm} .2016 .2586$

\begin{abstract}
There is an urgent need to improve the quality of donor organs obtained after cardiac death. In the present study, we examined the potential mechanisms through which A20 protects renal cells against ischemia/reperfusion injury (IRI) following either hypothermic machine perfusion (HMP) or static cold storage (CS) of the kidneys in a rabbit model. The expression of markers of apoptosis, necroptosis and inflammation in frozen kidney tissues were detected by western blot analysis, RT-qPCR and ELISA. Compared with the CS group, A20 expression was significantly higher in the tissue from the HMP group $(\mathrm{P}<0.01)$. By contrast, the expression of nuclear factor $-\kappa \mathrm{B}(\mathrm{NF}-\mathrm{\kappa B})$ and tumor necrosis factor- $\alpha$ (TNF- $\alpha$ ) was significantly lower in HMP group $(\mathrm{P}<0.01)$, whereas IкB $\alpha$ expression was significantly higher $(\mathrm{P}<0.01)$. The expression of apoptosis signal-regulating kinase 1 (ASK1), phosphorylated (p-)c-Jun N-terminal kinase (JNK) and activated caspase-3 in the HMP group was significantly downregulated compared with that in the CS group (all $\mathrm{P}<0.01$ ). In addition, A20 inhibited receptor-interacting protein kinase 3 (RIPK3)-mediated necroptosis in the kidney. RIPK3 expression in the HMP group was significantly lower than that in the CS group $(\mathrm{P}<0.01)$, although the levels in both groups were higher than those in the sham group $(\mathrm{P}<0.01)$. Based on these findings, we propose a novel mechanism underlying the anti-apoptotic effect of A20 in renal cells in which A20 binds to ASK1 and promotes the degradation of ASK1 leading to the suppression of JNK activation and eventually, to the blockade
\end{abstract}

Correspondence to: Dr Guizhu Peng or Dr Qifa Ye, Zhongnan Hospital of Wuhan University, Institute of Hepatobiliary Diseases of Wuhan University, Transplant Center of Wuhan University, Hubei Key Laboratory of Medical Technology on Transplantation, Wuhan, Hubei 430071, P.R. China

E-mail: 13807080901@139.com

E-mail: yqf-china@163.com

Key words: apoptosis, inflammation, necroptosis, A20, hypothermia machine perfusion, kidney of apoptosis. Thus, HMP reduces inflammation, apoptosis and necroptosis by upregulating the expression of A20; this mechanism may be responsible for protecting the kidney against IRI.

\section{Introduction}

Kidney transplantation is the optimal treatment for patients with end-stage renal disease (ESRD) (1); however, a severe shortage of organs is the permanent bottleneck which limits the availability of organ transplantation as a treatment. To increase the donor pool, novel and innovative means of increasing the number of suitable kidneys for transplantation have been established, including expanded criteria donation (ECD) and donation after cardiac death (DCD). However, the organs procured from DCD donors are at greater risk of serious ischemia-reperfusion injury (IRI). IRI is known to be a risk factor for delayed graft function (DGF), rejection, renal fibrosis and both poorer short- and long-term graft function as well as reduced patient survival following transplantation (2-5). Thus, methods to optimize the quality of DCD kidneys and improve short-term and long-term outcomes are urgently required. Hypothermic machine perfusion (HMP) and static cold storage (CS) are methods that have been developed over the past 30 years in order to maximize the benefit of donated kidneys (6). In fact, HMP has been reported to obtain better transplantation outcomes compared with CS (7-10). Although this potential benefit of HMP remains poorly understood, it may provide an opportunity to improve organ quality in combination with pharmacological and gene transfer therapies (11).

Inflammation is an invariable finding in acute and chronic kidney injury (12) and is a critical initiating and aggravating factor in kidney damage (13). A pivotal mediator of this inflammatory response is the transcription factor nuclear factor- $\mathrm{\kappa B}(\mathrm{NF}-\mathrm{\kappa B})$, which regulates the expression of adhesion molecules, chemokines and other pro-inflammatory molecules in renal or endothelial cells (ECs) (14-16). The best-characterized signaling pathways that lead to NF- $\mathrm{\kappa B}$ activation are those stimulated by members of the interleukin-1 (IL-1)/Toll-like receptor family and tumor necrosis factor- $\alpha$ (TNF- $\alpha)(17)$. 
Traditionally, two forms of cell death have been identified: apoptosis (programmed cell death) and necrosis (18). However, another form of cell death, known as necroptosis, has recently been identified which has the characteristics of apoptosis and necrosis (19). Evidence suggests that apoptotic pathways contribute to renal tubular injury $(20,21)$. Receptor-interacting protein kinase 3 (RIPK3)-mediated necroptosis in donor kidneys may promote inflammatory injury and has a major impact on renal IRI and graft survival (22).

A20, also known as tumor necrosis factor, alpha-induced protein 3(TNFAIP3), was originally identified as a TNF-inducible gene product of ECs (23). It has been demonstrated that A20 mRNA is markedly upregulated in the mouse kidney in response to TNF- $\alpha$ treatment, and A20 knockout mice are hypersensitive to the pro-inflammatory effects of TNF- $\alpha$ and lipopolysaccharide, which results in premature death due to severe multi-organ inflammation and cachexia $(24,25)$. A20 is a potent anti-inflammatory protein associated with multiple human autoimmune diseases and human malignancies $(26,27)$. A20 also enhances cell viability and has been shown to protect ECs, proximal tubular epithelial cells (TECs) and pancreatic islets from injury in response to various stimuli including TNF- $\alpha$ and oxidative stress (28-30). A20 is a cytoplasmic zinc-finger protein that has been characterized as a dual inhibitor of NF- $\kappa \mathrm{B}$ activation and cell death (31). Furthermore, A20 inhibits RIPK3-dependent necroptosis thereby attenuating inflammatory injury (32). Thus, measuring A20 at the mRNA and protein levels has the potential to be diagnostic and prognostic of transplantation outcomes and therefore may be important in determining timely therapeutic interventions in order to prolong graft survival (33). HMP is known to be superior to $\mathrm{CS}$ as a method of donor organ storage following cardiac death; therefore, in this study, we examined the molecular mechanism underlying the protective effects of HMP on donor organ storage.

\section{Materials and methods}

Animals. Eighteen healthy male rabbits (obtained from the Animal Experiment Center of Wuhan University/Wan Qian Jia He Experimental Animal Culture Center, Wuhan, China) weighing $3.1 \pm 0.2 \mathrm{~kg}$ (aged 12-13 weeks) were randomly allocated to three groups ( $n=6 /$ group).

All animal experiments were performed in accordance with the Experimental Animal Regulations established by The Ministry of Science and Technology of the People's Republic of China and the Guidelines for the Care and Use of Laboratory Animals published by the US National Institutes of Health. The study received ethics approval from the Ethics Committee of Zhongnan Hospital of Wuhan University. Prior to performing the experiments, all the animals were subjected to an overnight fast with unlimited access to water.

Establishment of the animal model. The rabbits were anesthetized and surgery was performed at the appropriate room temperature. In the sham group, the left kidney was subjected to warm ischemia for $25 \mathrm{~min}$ by clamping the left renal pedicle which was followed by reperfusion for $29 \mathrm{~h}$. In the HMP group, the left renal pedicle was clamped for $25 \mathrm{~min}$ which was followed by recovered blood flow for $1 \mathrm{~h}$. The kidneys were then hypothermically $\left(4-8^{\circ} \mathrm{C}\right)$ preserved in vivo for $4 \mathrm{~h}$ in
HCA-II solution (Shanghai Chang Zheng Hospital, Shanghai, China) using HMP $(n=6)$ or CS $(n=6)$. In the HMP group, the left kidneys were connected in vivo to the LifePort Kidney Transporter (Organ Recovery System, Chicago, IL, USA). A mean arterial pressure of $58 \pm 7.5 \mathrm{mmHg}$ was maintained during the period of perfusion. Following anastomosis of the vessels, a right nephrectomy was performed and specimens were obtained $24 \mathrm{~h}$ later. All procedures were identical in both groups, with the exception that the kidneys were stored in polystyrene organ boxes (Zhejiang Zhenhua Plastic Co., Ltd., Zhejiang, China) in the CS group.

Western blot analysis of A20, apoptosis signal-regulating kinase 1 (ASK1), c-Jun N-terminal kinase (JNK), phosphorylated (p-)JNK, pro-caspase-3, cleaved caspase-3, RIPK3, mucosa-associated lymphoid tissue lymphoma translocation gene 1 (MALT1), NF- $\kappa B$ and I $\kappa$ B $\alpha$ expression. The kidney tissue was homogenized in RIPA buffer containing a protease inhibitor and then centrifuged at $15,000 \mathrm{xg}$ for $20 \mathrm{~min}$ at $4^{\circ} \mathrm{C}$ in order to extract the total proteins. The supernatants were collected and the total protein concentrations were normalized using the BCA assay (Beyotime Institute of Biotechnology, Shanghai, China). The proteins were separated by $10-12 \%$ sodium dodecyl sulfate (SDS)-polyacrylamide gel electrophoresis and transferred to PVDF membranes (Millipore, Billerica, MA, USA). The blots were incubated with the antibodies specific for the following: A20 (RS-92803R), ASK1 (RS-90145R), MALT1 (RS-96863R) and I $\kappa \alpha$ (RS-90167R) (Shanghai Ruiqi Bio-Technology, Inc., Shanghai, China); caspase-3 (GB13009), and JNK (GB17018)/p-JNK (GB13019-M) (Wuhan Goodbio Technology, Inc., Hubei, China); NF-кB (bs-0465R) and RIPK3 (bs-3551R) (Bioss Bio Technology, Inc., Beijing, China). $\beta$-actin or GAPDH were used as controls. Following incubation with anti-IgG, the proteins were visualized using an ECL reagent followed by exposure to X-ray film. Quantification of band density was determined using the Quantity One software package (Bio-Rad Laboratories, Hercules, CA, USA).

Reverse transcription quantitative-polymerase chain reaction $(R T-q P C R)$. Total RNA was extracted from tissue using TRIzol reagent (Invitrogen, Carlsbad, CA, USA) according to the manufacturer's instructions. cDNA was synthesized using PrimeScript RT reagent kit with cDNA eraser (Invitrogen) according to the manufacturer's instructions. After PCR amplification, the products of A20, XIAP, GADD45 $\beta$, MnSOD and c-FLIP were separated by agarose gel electrophoresis and visualized by ethidium bromide staining. One-step real-time RT-PCR was performed using SYBR Premix Ex Taq $^{\mathrm{TM}}$ (Takara, Hubei, China) in a real-time PCR machine (ABI 7900; Applied Biosystems, Carlsbad, CA, USA) according to the manufacturers' instructions. The primer pairs used are listed in Table I. GAPDH and $\beta$-actin were used as endogenous controls. The relative mRNA expression levels of each target gene were normalized to those of the controls using the $2^{-\Delta \Delta \mathrm{CT}}$ method.

TdT-mediated biotin-16-dUTP nick-end labeling (TUNEL) assay. Apoptotic cell death was evaluated using the One-Step TUNEL Apoptosis assay kit (Beyotime Institute of Biotechnology). Briefly, the apoptotic cells were identified by the addition of digoxigenin-deoxynucleoside 
Table I. Sequences of rabbit primers used for comparative RT-qPCR.

\begin{tabular}{lll}
\hline Gene & \multicolumn{1}{c}{ Forward } & \multicolumn{1}{c}{ Reverse } \\
\hline A20 & 5'-AGACCGAGGAAGATTTGAAGAC-3' & 5'-CGTTAATCAGATGCGTCGTG-3' \\
ASK1 & 5'-GTTCGCCTTGGACAGTATCAT-3' & 5'-CTCGTGGTCATCTTCTACATCC-3' \\
IkB $\alpha$ & 5'-CCATCAACTACAACGGCCACA-3' & 5'-ACTTCAACAAGAGCGACACCAG-3' \\
XIAP & 5'-GAAGCCCAATGAAGACCCT-3' & 5'-CTCCCTGAAACTGAATCCC-3' \\
GADD45 3 & 5'-TCTTGGGTGATCGAGGACTGGC-3' & 5'-CGCCTCCTTCTTCTGTCTTTGCT-3' \\
MnSOD & 5'-CTTTGGGTCCTTTGACAAGTT-3' & 5'-AAGTGTCCCTGCTCCTTATTG-3' \\
c-FLIP & 5'-CCCAGCACCGAGACTATGA-3' & 5'-GCTTTGGCTTCCCTATGAG-3' \\
RIPK3 & 5'-GACCTCAAACCCTCCAACATC-3' \\
TNF- $\alpha$ & 5'-GCCGTCTCCTACCCGAACAAG-3' & 5'-CTAGACACTGCCTCTGCCAACT-3' \\
$\beta$-actin & 5'-TGGCTCTAACAGTCCGCCTAG-3' & 5'-CACAGGGCAATGATCCCAAAG-3' \\
HMGB1 & 5'-ATCCTGGCCTGTCCATTGGTG-3' & 5'-AGTGCGACGTGGACATCCG-3' \\
MALT1 & 5'-GCGATGCCTATGTCACCGATTT-3' & 5'-TTTCAGCCTTGACGACTCCCT-3' \\
GAPDH & 5'-GCTGAACGGGAAACTCACTG-3' & 5'-ACGTTCACCTCCTGCTTCTCCT-3' \\
\end{tabular}

ASK1, apoptosis signal-regulating kinase 1; XIAP, X-linked inhibitor of apoptosis protein; GADD45 $\beta$, growth arrest and DNA damage-inducible 45 $\beta$; MnSOD, manganese superoxide dismutase; c-FLIP, cellular FLICE-inhibitory proteins; RIPK3, receptor-interacting protein kinase 3; TNF- $\alpha$; tumor necrosis factor- $\alpha$; HMGB1, high mobility group box 1; MALT1, mucosa-associated lymphoid tissue lymphoma translocation gene 1 .

triphosphate (dNTP) fragments to the 3'-OH DNA termini by TdT followed by labeling with peroxidase- or rhodamine-linked anti-digoxigenin antibodies and visualization with either diaminobenzidine (DAB; Beyotime Institute of Biotechnology) followed by light microscopy or fluorescence microscopy (Olympus Corporation, Tokyo, Japan). As a positive control, sections were incubated with DNase I for $10 \mathrm{~min}$ at room temperature $\left(25^{\circ} \mathrm{C}\right)$ prior to the fluorescent labeling procedure. The cells labeled with green fluorescence were described as apoptotic cells. The cells were labeled with 4',6-diamidino-2-phenylindole (DAPI; Beyotime Institute of Biotechnology) for nuclear staining.

Immunohistochemical analysis of A20 and RIPK3 expression. The expression of A20 and RIPK3 in paraffin-embedded tissue sectionswasanalyzedbyimmunohistochemistry(IHC).Following deparaffinization and antigen retrieval in $10 \mathrm{mM}$ sodium citrate buffer (pH 6.0) using the pressure cooker method at full power for $4 \mathrm{~min}$, the tissue sections were exposed to $3 \% \mathrm{H}_{2} \mathrm{O}_{2}$ for $10 \mathrm{~min}$. The tissue sections were then blocked for $30 \mathrm{~min}$ at room temperature with $5 \%$ bovine serum albumin (BSA). The sections were incubated with anti-A20 (1:40) and anti-RIPK3 (1:200) antibodies overnight at $4^{\circ} \mathrm{C}$ in a humid chamber and then incubated with the horseradish peroxidase (HRP)-conjugated secondary detection antibody for $30 \mathrm{~min}$ at $37^{\circ} \mathrm{C}$. The sections were then incubated with DAB chromogen, counterstained with hematoxylin (Beyotime Institute of Biotechnology) and finally dehydrated, cleared and mounted with neutral gum. The sections were washed with several changes of Tris-buffered saline (TBS)$0.3 \%$ Tween buffer between each step.

Enzyme-linked immunosorbent assay (ELISA). TNF- $\alpha$ levels were measured using a specific ELISA kit (Elabscience Biotechnology Co., Ltd., Hubei, China) according to the manufacturer's instructions. The homogenates were first centrifuged at $10,000 \mathrm{x} \mathrm{g}$ for $25 \mathrm{~min}$ in order to remove solid tissue debris and the supernatant was collected and assayed.

Measurement of reactive oxygen species (ROS) and malonaldehyde (MDA) levels. The levels of ROS and MDA are established markers used to determine the extent of tissue oxidative damage and cell viability. The kidney tissues were thawed following homogenization according to the manufacturer's instructions. (Jiancheng Technology Co., Ltd., Nanjing, China). The supernatant was assayed using the Multiskan MK3 (Thermo Fisher Scientific, Waltham, MA, USA).

Statistical analysis. The results are presented as the means \pm standard deviation (SD). Statistical analysis was performed by one-way analysis of variance (ANOVA) after proving the assumption of normality (Shapiro-Wilk testing) and then followed by LSD multiple comparison tests when F was significant. The software SPSS 17.0 for Windows (SPSS, Inc., Chicago, IL, USA) was used. $\mathrm{P}<0.05$ was considered to indicate a statistically significant difference.

\section{Results}

Expression of A20, but not of other $N F-\kappa B$ target genes significantly increases in the HMP group compared with that in the CS group. Fig. 1A shows the results of the analysis of A20 and MALT1 expression obtained by western blot analysis and RT-qPCR in the different treatment groups. HMP treatment significantly increased A20 expression compared with that in the CS group $(\mathrm{P}<0.01)$. The expression of MALT1 (in the kidney), which cleaves A20 (34), in the HMP group was lower than that in the CS group $(\mathrm{P}<0.01)$. Fig. $1 \mathrm{~B}$ and $\mathrm{C}$ show the results of RT-qPCR of A20, X-linked inhibitor of apoptosis protein (XIAP), manganese superoxide dismutase (MnSOD), growth arrest and DNA damage-inducible $45 \beta$ (GADD45 $\beta$ ) 

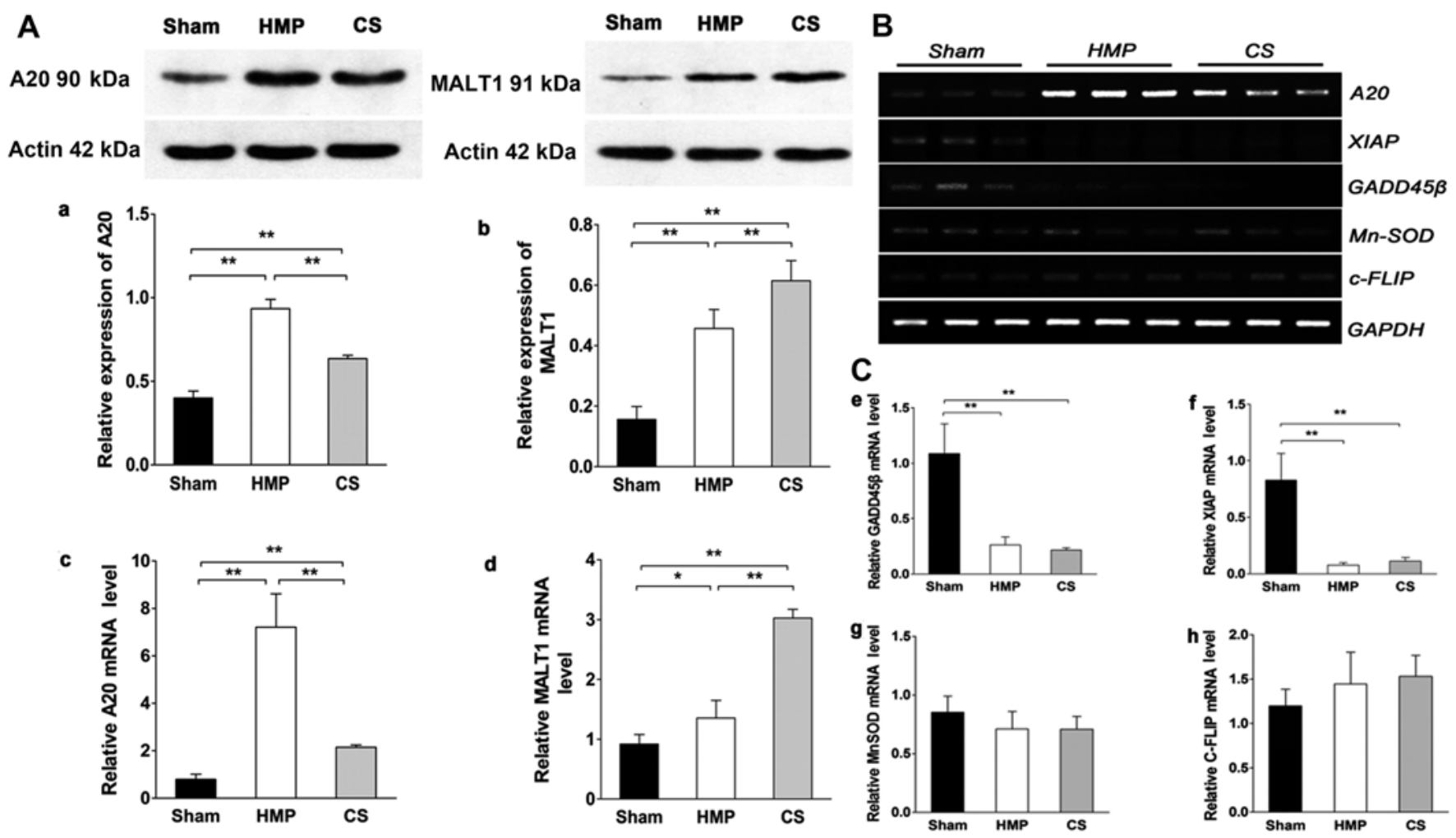

Figure 1. (A) A20 and mucosa-associated lymphoid tissue lymphoma translocation gene 1 (MALT1) expression in the three groups were analyzed by western blot analysis and RT-qPCR. Representative blots are shown. Western blot analysis of (a) A20 and (b) MALT1 protein. $\beta$-actin was used as the control. RT-qPCR analysis of (c) A20 and (d) MALT1 mRNA levels. Graphs represent the statistical analysis of relative A20 mRNA levels after normalization against $\beta$-actin. In the hypothermic machine perfusion (HMP) group, A20 expression was increased compared with that in the cold storage $(\mathrm{CS})$ and sham groups $\left(\right.$ both $\left.{ }^{* *} \mathrm{P}<0.01\right)$. By contrast, MALT1 expression was reduced compared with that in the CS group $\left({ }^{* *} \mathrm{P}<0.01\right)$. Results represent the means $\pm \mathrm{SD}$ of three experiments, ${ }^{*} \mathrm{P}<0.05$. (B and $\mathrm{C})$ In the HMP group, the expression of $\mathrm{A} 20$, but not of other nuclear factor- $\kappa \mathrm{B}(\mathrm{NF}-\kappa \mathrm{B})$ target genes was significantly increased compared with the levels in the CS group. Levels of particular transcripts were quantified by real-time PCR using gene-specific primers. The amount of each target transcript was normalized against the levels of GAPDH transcript. (B) The mRNA expression of A20, XIAP, GADD45 $\beta$, MnSOD and c-FLIP was examined in renal tissue. After PCR amplification, the products were separated by agarose gel electrophoresis and visualized by ethidium bromide staining. (C-e-g) Compared with the sham group, X-linked inhibitor of apoptosis protein (XIAP) and growth arrest and DNA damage-inducible $45 \beta$ (GADD $45 \beta$ ) were marginally or poorly induced (all ${ }^{* *} \mathrm{P}<0.01$ ), whereas manganese superoxide dismutase (MnSOD) levels were slightly lower in both the HMP and CS groups compared with those in the sham group (both P>0.05). (h) Both the HMP and CS groups showed increased expression of cellular FLICE-inhibitory proteins (c-FLIP) compared with that in the sham group, although there were no significant differences among the three groups. Data represent the means \pm SD of three experiments.

and cellular FLICE-inhibitory proteins (c-FLIP) expression in the different treatment groups. It has been proposed that a subset of $\mathrm{NF}-\kappa \mathrm{B}$ target genes, including XIAP, MnSOD, GADD $45 \beta$, and c-FLIP, are capable of antagonizing JNK signaling (35-37). In the present study, the expression of XIAP and GADD $45 \beta$ were marginally or poorly induced whereas MnSOD levels were slightly lower in both the HMP and CS groups compared with those in the sham group. Although the expression of c-FLIP was increased in both the HMP and CS groups compared with that in the sham group, there was no significant difference among the three groups. Thus, these findings clearly indicate that A20 rather than the JNK inhibitors, plays a predominant role in the suppression of JNK signaling in apoptosis.

Immunohistochemical analysis reveals higher A20 expression in the HMP group compared with that in the CS group. The immunohistochemical analysis of the location and levels of A20 expression in the kidneys in the HMP and CS groups is shown in Fig. 2. A20 was expressed predominantly in the TECs, with significantly more abundant expression observed in the HMP group compared with that in the CS group $(\mathrm{P}<0.01)$.
Extent of kidney injury significantly decreases in the HMP group compared with that in the CS group. Renal cellular injury was detected by the measurement of ROS levels and MDA, which are important indicators of oxidative damage. Significantly higher levels of ROS and MDA were detected in the CS group compared with those in the HMP group (both $\mathrm{P}<0.01$ ) (Fig. 3).

Inflammation of the kidneys decreased in the HMP group compared with that in the CS group. In the basal state, $\mathrm{NF}-\kappa \mathrm{B}$ is sequestered in the cytoplasm by inhibitory I $\mathrm{B}$ proteins. When I $\mathrm{B}$ kinase $\beta$ (IKK $\beta$ ) is activated by proinflammatory signaling, it triggers the degradation of I $\mathrm{B} \alpha$, thereby promoting the nuclear translocation and activation of $\mathrm{NF}-\kappa \mathrm{B}$. To verify the degree of inflammation in the kidney, we analyzed the levels of TNF- $\alpha$ by ELISA and RT-qPCR. Furthermore, we evaluated the expression levels of NF- $\kappa \mathrm{B}$ and I $\mathrm{B} \alpha$ using western blot analysis and RT-qPCR. The HMP group showed significantly decreased levels of TNF- $\alpha$ and $\mathrm{NF}-\kappa \mathrm{B}$ compared with those in the CS group (both $\mathrm{P}<0.01$ ), whereas there was no significant difference in the expression of TNF- $\alpha$ between the HMP and sham group $(\mathrm{P}>0.05)$. By contrast, the expression of I $\mathrm{B} \alpha$ in the HMP group was signifi- 


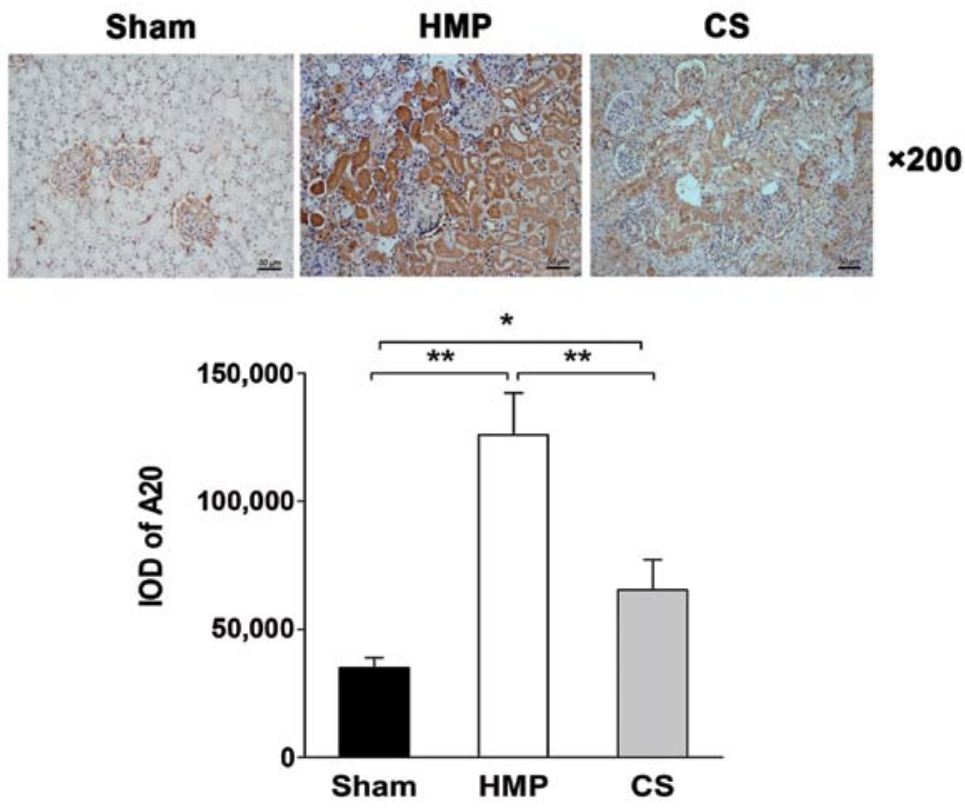

Figure 2. Immunohistochemical analysis of the location and levels of A20 expression in the kidneys in the hypothermic machine perfusion (HMP) and cold storage (CS) groups. The HMP group showed significantly increased expression of A20 compared with that in the CS and sham groups (both $\left.{ }^{* * *} \mathrm{P}<0.01\right)$. In the HMP and CS groups, A20 was predominantly expressed in the tubular epithelial cells. There were five slices in each group and positive cells were counted within three horizons for each slice. ${ }^{*} \mathrm{P}<0.05$.
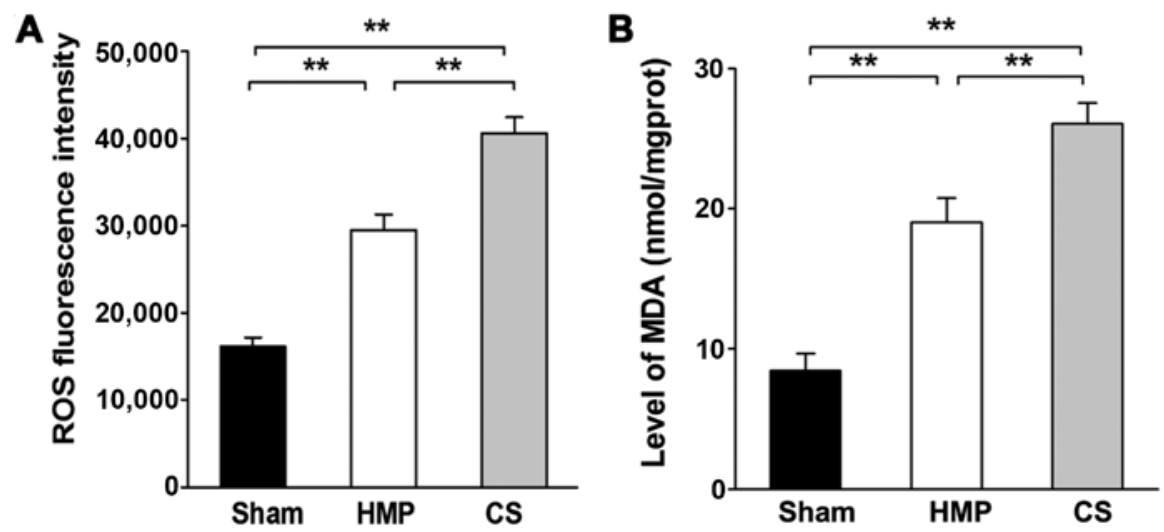

Figure 3. Measurement of reactive oxygen species (ROS) and malonaldehyde (MDA) levels in the three groups in order to evaluate the extent of kidney injury. (A) The cold storage (CS) group had significantly increased ROS levels compared with the those in the hypothermic machine perfusion (HMP) and sham groups (both $\left.{ }^{* *} \mathrm{P}<0.01\right)$. (B) The CS group showed significantly increased MDA levels compared with those in the HMP and sham groups (both ${ }^{* *} \mathrm{P}<0.01$ ). Results represent the means \pm SD of three experiments.

cantly higher than that in the CS group (protein level, $\mathrm{P}<0.01$; mRNA level, $\mathrm{P}<0.05$ ) (Fig. 4).

Apoptosis of renal cells significantly decreases in the HMP group compared with that in the CS group. We detected apoptosis of renal cells using TUNEL assay. The rate of apoptosis was approximately 4-fold lower in the HMP group compared with that in the CS group $(\mathrm{P}<0.01)$ (Fig. 5), HMP $3.48 \pm 0.5 \%$, and CS $13.77 \pm 2.0 \%$.

Expression of ASK1,p-JNKand cleaved caspase-3 significantly decreases in the HMP group compared with that in the CS group. To evaluate whether A20 decreased apoptosis through the ASK1-JNK pathway, the expression of ASK1, JNK and its activated form $\mathrm{p}-\mathrm{JNK}$ were evaluated by western blot analysis and RT-qPCR (Fig. 6). HMP treatment reduced the activation of ASK1, JNK, specifically reducing the expression of p-JNK compared with that in the CS group (all $\mathrm{P}<0.01$ ). Compared with the CS group, pro-caspase-3 expression was decreased in the HMP group $(\mathrm{P}<0.05)$; furthermore, the expression of its activated form was more significantly decreased in the HMP group $(\mathrm{P}<0.01)$. Compared with the sham group, both the HMP and CS groups showed increased expression of p-JNK and cleaved caspase-3 (all P<0.01) (Fig. 6).

RIPK3 expression significantly decreases compared with that in the CS group. RIPK3 expression was evaluated by western blot analysis and RT-qPCR (Fig. 7). RIPK3 expression was significantly lower in the HMP group compared with that in the CS group $(\mathrm{P}<0.01)$. Compared with the sham group, both the HMP 

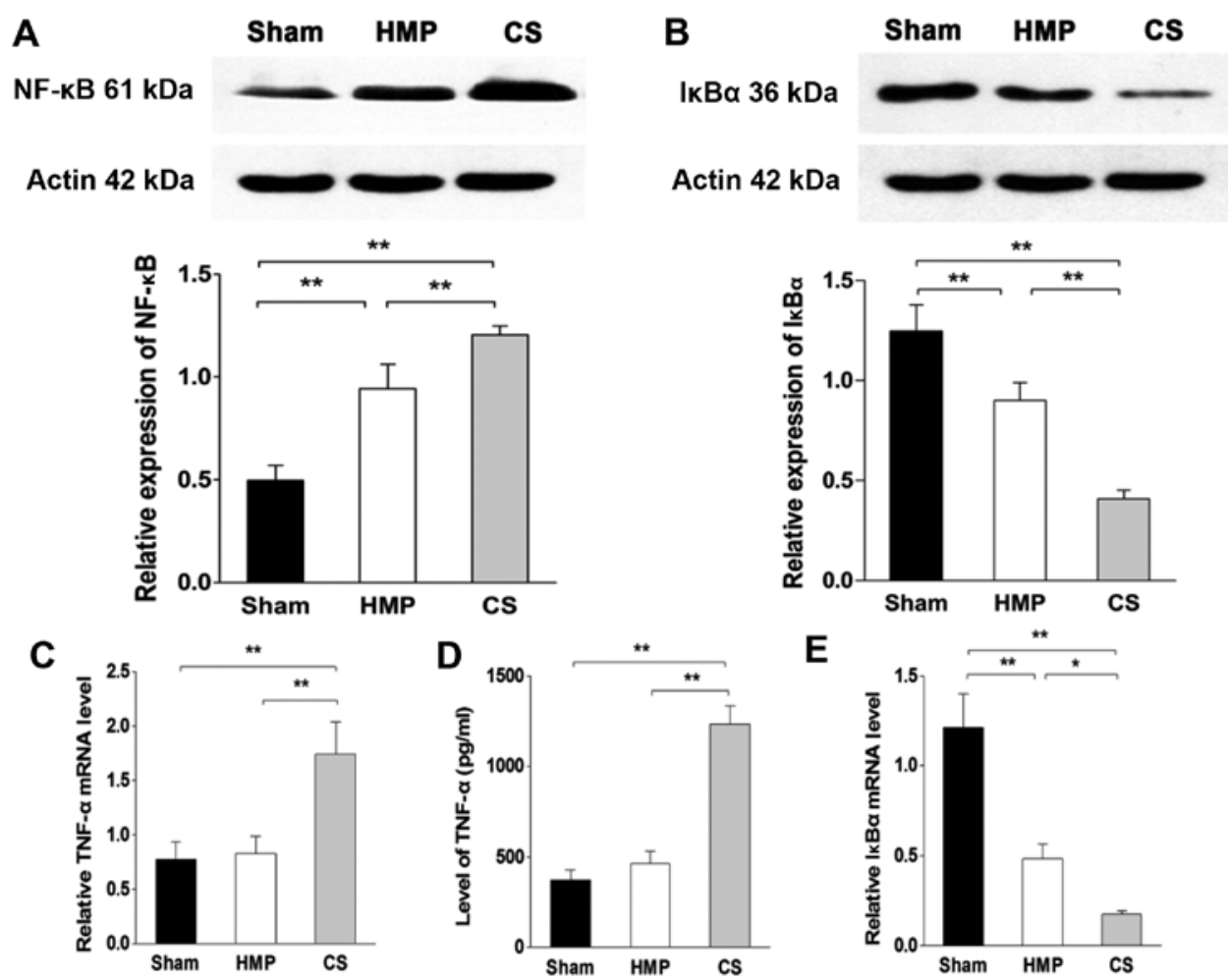

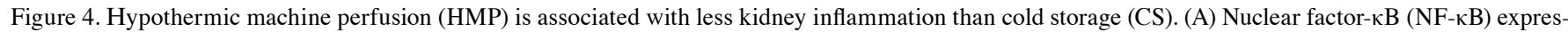
sion was evaluated by western blot analysis. The HMP group showed significantly decreased NF- $\mathrm{kB}$ expression compared with that in the CS group $\left({ }^{* *} \mathrm{P}<0.01\right)$.

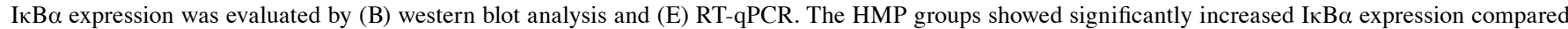
with that in the CS group $\left({ }^{* *} \mathrm{P}<0.01,{ }^{*} \mathrm{P}<0.05\right)$. Tumor necrosis factor- $\alpha$ (TNF- $\alpha$ ) expression was detected by (C) RT-qPCR and (D) ELISA. The HMP group showed significantly decreased TNF- $\alpha$ expression at both the protein and mRNA levels compared with that in the CS group ("** $\mathrm{P}<0.01)$ whereas there was no significant difference in the expression of TNF- $\alpha$ between the HMP and sham groups $(\mathrm{P}>0.05)$. Results represent the means $\pm \mathrm{SD}$ of three experiments.
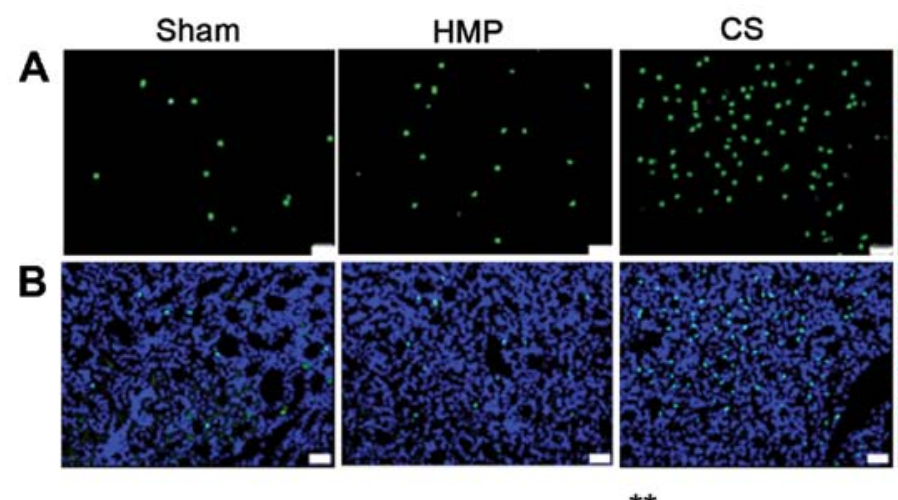

Positive control

C

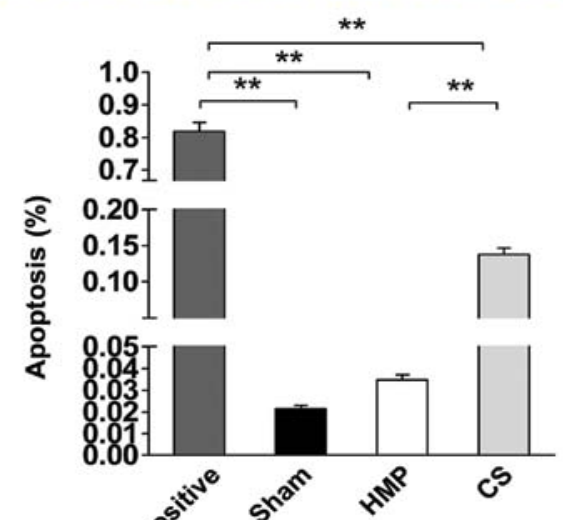

Figure 5. Detection of apoptosis of renal cells by the TdT-mediated biotin-16-dUTP nick-end labeling (TUNEL) assay. The kidney sections were stained with 4',6-diamidino-2-phenylindole (DAPI) in order to identify the nuclei. The rates of apoptosis in the positive control group confirmed the validity of the TUNEL assay results. (A) Apoptosis was significantly decreased in the hypothermic machine perfusion (HMP) group compared with that in the cold storage (CS) group $(" \mathrm{P}<0.01)$. (B) A superimposed high power image. Nuclear counter staining by DAPI. (C) Quantitative analysis of apoptosis. ${ }^{*} \mathrm{P}<0.01$. Results represent the means \pm SD ( $=5$, magnification, $\mathrm{x} 200$ ). 
A

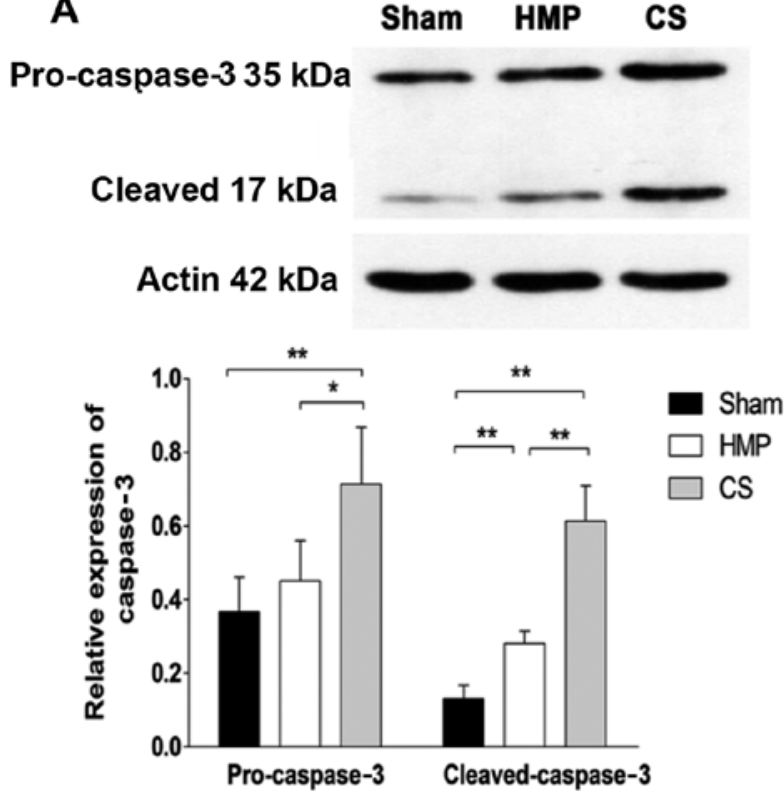

C
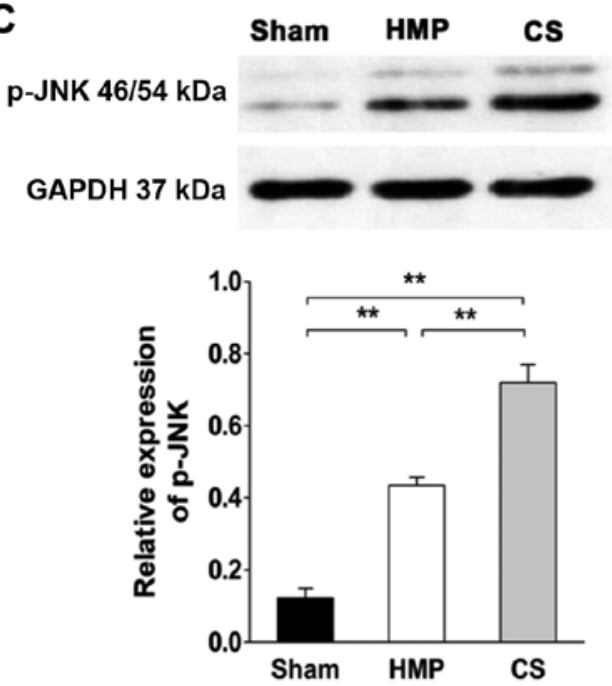

D

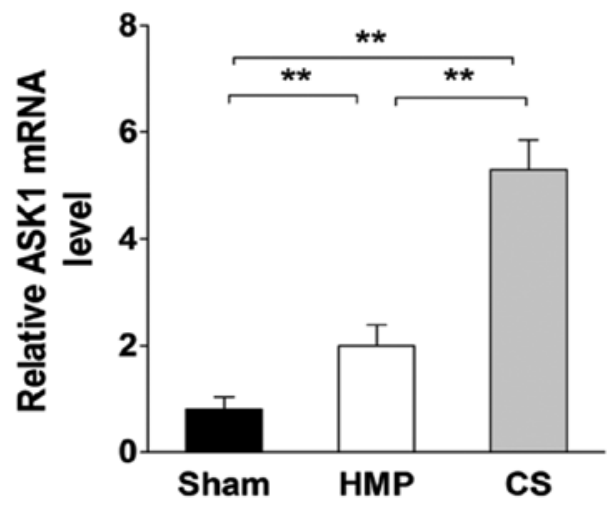

B

Sham

HMP

cS

ASK1 $155 \mathrm{kDa}$

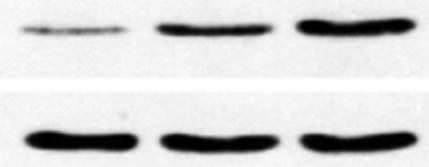

Actin $42 \mathrm{kDa}$
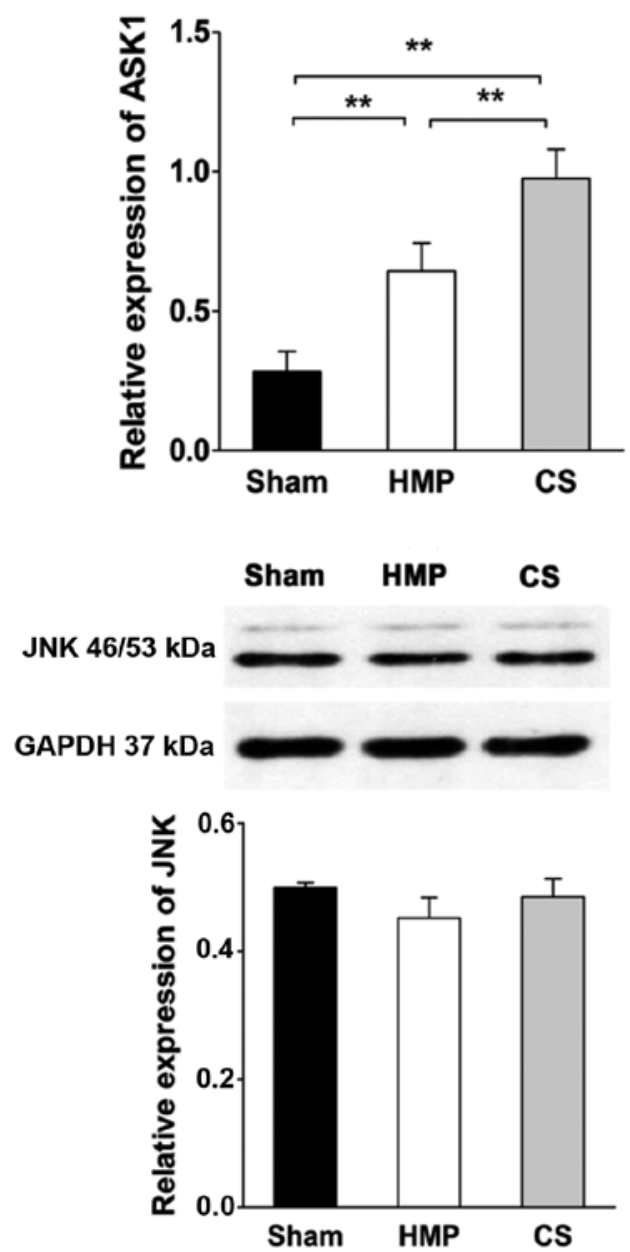

E

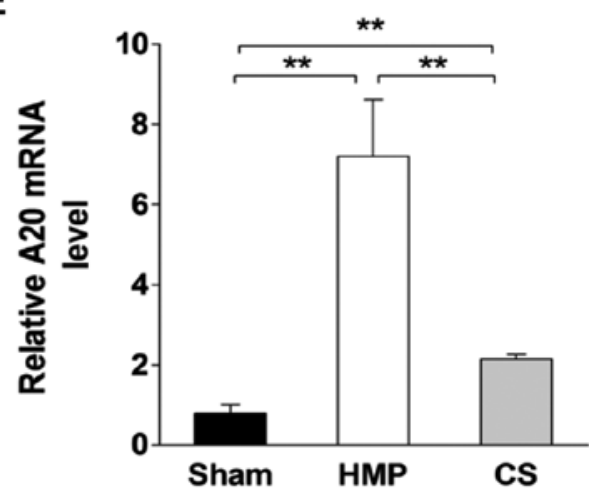

Figure 6. Evaluation of the expression of apoptosis signal-regulating kinase 1 (ASK1), c-Jun N-terminal kinase (JNK), phosphorylated (p-)JNK, pro-caspase-3 and cleaved caspase- 3 by western blot analysis and RT-qPCR. Representative blots are shown. $\beta$-actin or GAPDH were used as controls. Levels of particular transcripts were quantified by real-time PCR using gene-specific primers. The amount of each target transcript was normalized by measuring $\beta$-actin transcript levels. (A) Procaspase-3 levels in the hypothermic machine perfusion (HMP) group were significantly reduced compared with those in the cold storage (CS) group ( $(\mathrm{P}<0.05)$ and the cleaved caspase-3 levels in the HMP group were significantly lower than those in the CS group $\left({ }^{* *} \mathrm{P}<0.01\right)$. Compared with the sham group, both the HMP and CS groups showed increased expression of cleaved caspase-3 (both ${ }^{* *} \mathrm{P}<0.01$ ). (B and D) The HMP group exhibited reduced ASK1 expression at both the protein and mRNA levels compared with the CS group ( $\left.{ }^{* *} \mathrm{P}<0.01\right)$. (C) Compared with the sham group, both the HMP and CS groups showed reduced expression of total JNK, although this effect was not statistically significant. The expression of p-JNK was significantly reduced in the HMP group compared with that in the CS group $\left({ }^{* * *} \mathrm{P}<0.01\right)$. (E) Compared with the sham and CS groups, the mRNA expression of A20 was significantly increased in the HMP group $\left({ }^{* * *} \mathrm{P}<0.01\right)$. Data represent the means \pm SD of three experiments. 

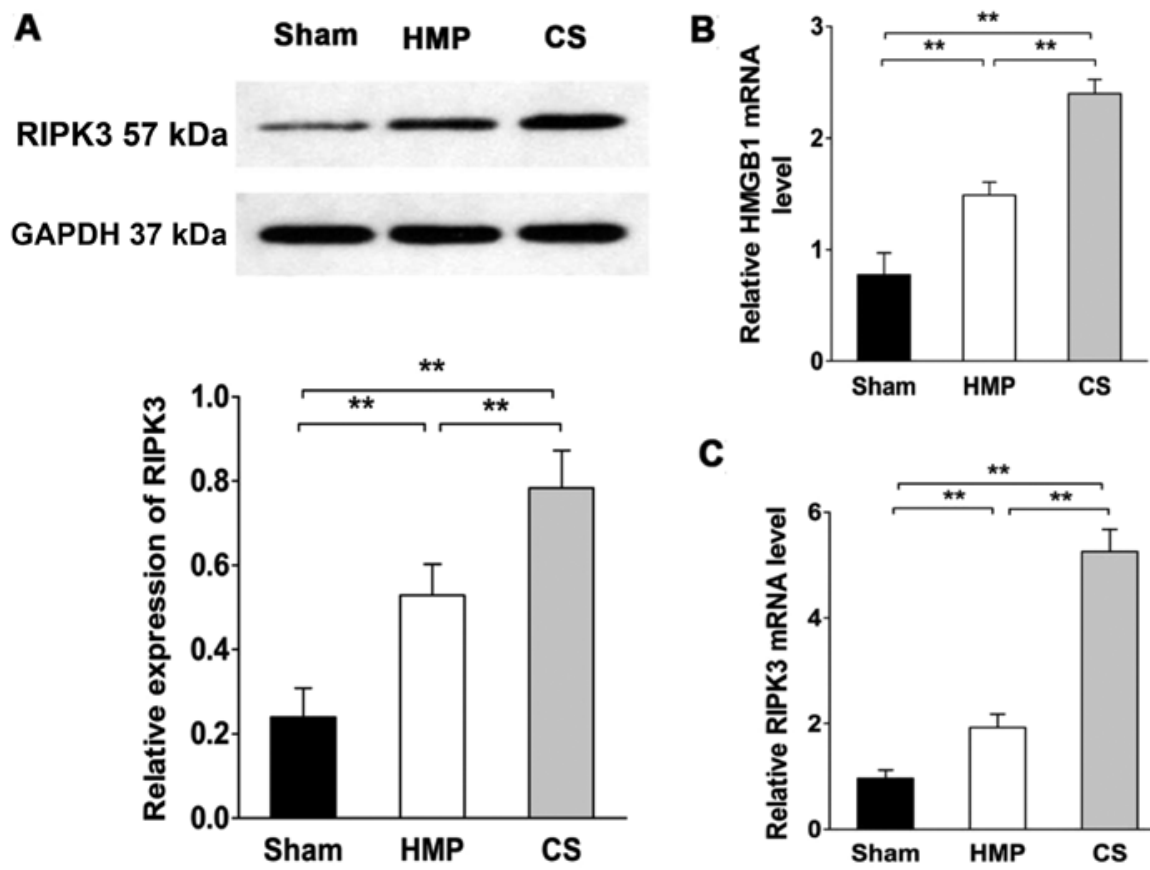

C

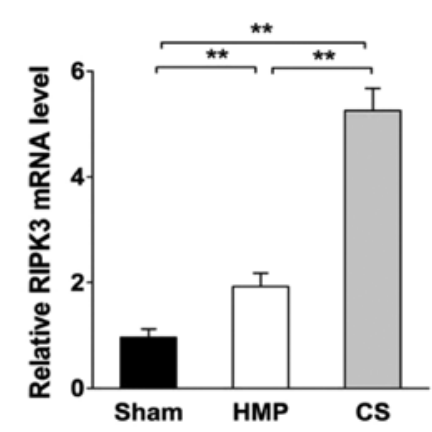

Figure 7. Receptor-interacting serine-threonine kinase 3 (RIPK3) and high mobility group box 1 (HMGB1) expression significantly decreases in the hypothermic machine perfusion (HMP) group compared with that in the cold storage (CS) group. RIPK3 expression was evaluated by western blot analysis and RT-qPCR using GAPDH as a loading control. The expression of HMGB1 expression was analyzed by RT-qPCR as a marker of necroptosis. The amount of transcript was normalized by measuring GAPDH transcript levels. (A and C) RIPK3 expression in the HMP group was significantly lower than that in the CS group $\left({ }^{* *} \mathrm{P}<0.01\right)$. Compared with the sham group, both the HMP and CS groups showed increased expression of RIPK3 (both $\left.{ }^{* *} \mathrm{P}<0.01\right)$. (B) The HMP group exhibited reduced HMGB1 expression compared with the CS group ( $\left.{ }^{* *} \mathrm{P}<0.01\right)$. Results represent the means \pm SD of three experiments.

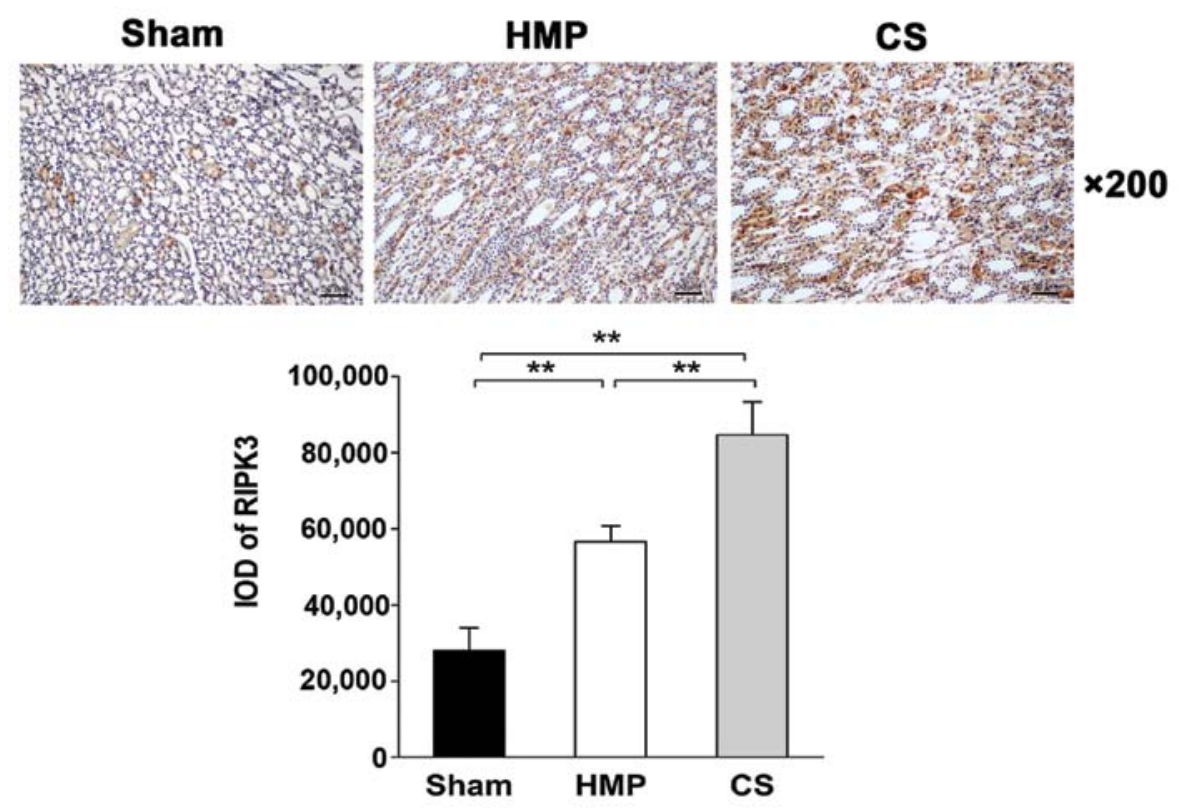

Figure 8. Immunohistochemical analysis of the expression and location of RIPK3. Representative images are shown (magnification, x200). RIPK3 expression was significantly reduced in the hypothermic machine perfusion (HMP) group compared with that in the cold storage (CS) group $\left({ }^{* *} \mathrm{P}<0.01\right)$. RIPK3 protein was expressed mainly in the tubular epithelial cells. There were five slices in each group and positive cells were counted within three horizons for each slice.

and CS groups showed increased expression of RIPK3 (both $\mathrm{P}<0.01$ ). We also measured high mobility group box 1 (HMGB1) release in order to confirm the necrosis of renal cells (38). HMGB1 expression was significantly lower in the HMP group compared with that in the CS group $(\mathrm{P}<0.01)$. Both the HMP and CS groups showed increased expression of HMGB1 compared with that in the sham group (both $\mathrm{P}<0.01$ ).
Immunohistochemical analysis of paraffin-embedded sections reveals low RIPK3 expression in the HMP group. The expression and location of RIPK3 in the kidney was analyzed by IHC. Only low levels of RIPK3 protein was expressed in the HMP group, whereas significantly higher levels were detected in the CS group $(\mathrm{P}<0.01)$. RIPK3 protein was expressed mainly in the TECs (Fig. 8). 


\section{Discussion}

The renal transplant waiting list continues to grow each year, as does the demand for donor organs. To expand the existing pool of organs, the use of kidneys obtained from donors after cardiac death is increasing in most countries. However, there is ongoing controversy regarding the quality of some DCD and ECD grafts compared with standard criteria organs. Such allografts are prone to higher rates of DGF, primary non-function and decreased long-term graft survival $(5,39,40)$. The findings of the multicenter Eurotransplant trial published in 2009 demonstrated that HMP reduced the incidence of DGF (26.5\% with CS to $20.8 \%$ with HMP) in kidneys obtained from the most common types of deceased donors (8). The three-year follow-up data from this trial also demonstrated improved graft survival with HMP (9). HMP is known to be more appropriate for donor organ storage after cardiac death than CS; however, clarification of the underlying mechanism is urgently required in order to further improve donor organ quality through HMP.

Kidney transplantation is invariably associated with organ damage, including IRI. Following an ischemic episode, the apoptosis and necrosis of TECs occurs initially, and the following EC injury further exacerbates ongoing ischemia of the tubular epithelium as well as the inflammatory response $(41,42)$. TECs are known to be the most susceptible cell type to inflammatory injury, which results in tubular necrosis (43). A previous study has shown the benefit of blocking necroptosis in renal IRI (44). In addition, apoptosis is one of the principal causes of cell death in isolated kidneys and cultured renal tubular cells following IRI (45). Therefore, controlling inflammation and cell death, particularly of TECs, is an attractive therapeutic strategy to reverse acute kidney injury, halt chronic disease and protect renal allografts.

The anti-inflammatory function of A20 is well documented in A20 knockout mice, which are cachectic at birth and die within 3 weeks of birth as a result of uncontrolled inflammation (24). Moreover, TNF- $\alpha$ markedly increases A20 mRNA expression in the kidney (24) and da Silva et al demonstrated that inflammation induces the NF- $\mathrm{KB}$-dependent protein A20 in human renal proximal TECs (RPTECs) (46). These findings are consistent with our results demonstrating that A20 is expressed in rabbit TECs. Hypoxia stimulates NF- $\mathrm{KB}$ signaling in epithelial and macrophage cell lines by preventing the repression of IKK $\beta$ by oxygen-dependent prolyl hydroxylases (47). In addition, NF- $\mathrm{KB}$ may be activated during ischemia/reperfusion (I/R) by changes in the cellular redox potential, which occurs in response to hypoxia (during ischemia) followed by re-oxygenation (during reperfusion) (48). NF- $\kappa \mathrm{B}$ transcription factors act as central regulators of inflammation (16). NF- $\mathrm{KB}$ is usually sequestered in the cytoplasm in association with

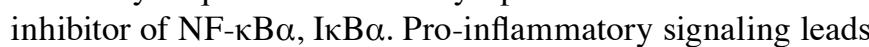
to IкB $\alpha$ degradation, thereby promoting the nuclear translocation and activation of NF- $\mathrm{KB}$. It is well established that A20, as one of the NF- $\mathrm{KB}$ target genes, is involved in a negative feedback loop to block NF- $\kappa B$ activation $(24,31)$. It has been demonstrated that $\mathrm{A} 20$ protects vascular ECs, hepatocytes and pancreatic $\beta$ cells from inflammation (49-51). This is consistent with our results showing the potent anti-inflammatory effect of A20 in TECs. In the HMP group, A20 reduced the expression of NF- $\mathrm{KB}$ and TNF- $\alpha$ compared with that in the CS group.
A20 was initially characterized as an inhibitor of TNF-induced apoptosis (52). As an anti-apoptotic protein, A20 has been demonstrated to protect breast cancer MCF-7 cells, fibrosarcoma WEHI164 cells, embryonic fibroblast NIH 3T3 cells, ECs and L929 cells from TNF-mediated apoptosis or necrosis $(28,52-$ 54). A20 acts early in the TNF- $\alpha$-induced signaling cascade by blocking both TNF- $\alpha$-induced rapid activation of JNK and processing of the receptor-associated caspase-8 (55). Daniel et al also showed that A20 targets the TNF- $\alpha$-induced apoptotic pathway by inhibiting the proteolytic cleavage of caspases- 8 and -2 as well as caspases-3 and -6 (28). Caspase inhibition using shRNA in order to silence caspase- 8 or transgenic overexpression of the endogenous caspase-8 inhibitor c-FLIP has been shown to protect renal TECs against TNF- $\alpha$-induced apoptosis in vitro and ischemic kidney injury in vivo $(56,57)$. As an alternative mechanism underlying the anti-apoptotic effects of A20, Won et al proposed that A20 binds to ASK1, an important mitogen-activated protein kinase kinase (MAPKK) kinase in the JNK signaling cascade, and mediates ASK1 degradation, leading to the suppression of JNK activation and eventually the inhibition of apoptosis (58). Moreover, A20 may inhibit apoptosis through the suppression of pro-inflammatory cytokines (59). The mitochondria, an organelle found in most cells, are key sites for integrating the death receptor and mitochondrial apoptotic pathway during exogenous stress (60). The caspase family plays an important role in mediating apoptosis. Among them, caspase-3 acts as a key execution molecule that functions in many ways in the transduction of apoptotic signals (61). In the present study, we found that A20 expression in the HMP group was significantly increased compared with that in the CS group. Furthermore, the results of western blot analysis or RT-qPCR revealed that the expression of ASK1, p-JNK and cleaved caspase-3 was significantly reduced compared with that in the CS group. Moreover, TUNEL assay analysis of apoptosis in our study showed that the rate of apoptosis was approximately 4 -fold lower in the HMP group compared with that in the CS group. These results are consistent with those of a previous study showing 5 -fold lower levels of myocyte apoptosis in the HMP group compared with those in the CS group in an ex vivo rat heart transplantation model (62). In the present study, we demonstrated that A20 is predominantly expressed in the TECs, with significantly more abundant expression in the HMP group compared with that in the CS group. This suggests that HMP decreased the rate of renal cell apoptosis and the subsequent apoptotic cell death pathway during IRI by suppressing the ASK1-JNK signaling cascade.

Generally, necroptosis is defined as cell death mediated through a pathway that depends on the RIPK1-RIPK3 complex that may be inhibited by necrostatin-1 (Nec-1) (63). Necroptosis is induced by a class of death receptors that includes tumor necrosis factor receptor (TNFR)1, TNFR2 and Fas. Among them, the TNF- $\alpha$ /TNFR-induced pathway is the most widely studied. Necroptotic death typically triggers inflammation in vivo due to the release of intracellular molecules from dying cells (19). Necrosis results in the loss of membrane integrity and the release of HMGB1 and other damage-associated molecular patterns (DAMPs) that promote inflammatory responses $(64,65)$. The contribution of RIPK1-dependent necroptosis to kidney failure has also been observed in models of I/R and it may rescued by Nec-1 inhibitor (44). A recently study showed that $\mathrm{RIPK} 1 / 3$ is a regulator of TNF- $\alpha$-mediated necroptosis in renal 
TECs and RIPK3-deficient allografts had improved renal function and longer rejection-free survival compared with kidneys from wild-type mice (22). Recently Onizawa et al showed that A20 used its deubiquitinating motif to restrict RIPK3 ubiquitination and the formation of necroptotic RIPK1-RIPK3 complexes and also restricted RIPK3-dependent necroptosis in multiple cell types, although not in renal cells (32). In the present study, RIPK3 protein was expressed mainly in the TECs and in the HMP group, RIPK3 expression was significantly lower than that in the CS group. In addition the HMP group exhibited reduced HMGB1 expression compared with that in the CS group. These results indicate that, compared with CS, HMP induces greater A20 expression during IRI, hence restricting RIPK3-dependent necroptosis and inflammation in TECs.

In the present study, we have demonstrated that A20 may be induced at low temperatures, and that HMP significantly increases A20 expression compared with CS. Thus, we concluded that HMP significantly inhibits inflammation and decreases the apoptosis and necroptosis of renal cells during IRI by inducing the expression of A20. With regard to the mechanism, we suggest that the higher levels of A20 expression in the HMP group are due to the lower levels of MALT1, which cleaves A20 (34), compared with those in the CS group; however the detailed mechanism remains to be fully elucidated and further studies are required to better delineate the molecular targets of A20 in organs stored using the HMP technique.

\section{Acknowledgements}

The present study was funded by the National Natural Science Foundation of China (grant no. 81570079).

\section{References}

1. Wolfe RA, Ashby VB, Milford EL, Ojo AO, Ettenger RE Agodoa LY, Held PJ and Port FK: Comparison of mortality in all patients on dialysis, patients on dialysis awaiting transplantation, and recipients of a first cadaveric transplant. N Engl J Med 341: 1725-1730, 1999.

2. Nicholson ML, Metcalfe MS, White SA, Waller JR, Doughman TM, Horsburgh T, Feehally J, Carr SJ and Veitch PS: A comparison of the results of renal transplantation from non-heart-beating, conventional cadaveric, and living donors. Kidney Int 58: 2585-2591, 2000.

3. Perico N, Cattaneo D, Sayegh MH and Remuzzi G: Delayed graft function in kidney transplantation. Lancet 364: 1814-1827, 2004.

4. Curci C, Castellano G, Stasi A, Divella C, Loverre A, Gigante M Simone S, Cariello M, Montinaro V, Lucarelli G, et al: Endothelial-to-mesenchymal transition and renal fibrosis in ischaemia/reperfusion injury are mediated by complement anaphylatoxins and Akt pathway. Nephrol Dial Transplant 29: 799-808, 2014

5. Gueler F, Gwinner W, Schwarz A and Haller H: Long-term effects of acute ischemia and reperfusion injury. Kidney Int 66: $523-527,2004$

6. Kosieradzki M and Rowiński W: Ischemia/reperfusion injury in kidney transplantation: mechanisms and prevention. Transplant Proc 40: 3279-3288, 2008.

7. St Peter SD, Imber CJ and Friend PJ: Liver and kidney preservation by perfusion. Lancet 359: 604-613, 2002.

8. Moers C, Smits JM, Maathuis MH, Treckmann J, van Gelder F, Napieralski BP, van Kasterop-Kutz M, van der Heide JJ, Squifflet JP, van Heurn E, et al: Machine perfusion or cold storage in deceased-donor kidney transplantation. N Engl J Med 360: 7-19, 2009.

9. Moers C, Pirenne J, Paul A and Ploeg RJ; Machine Preservation Trial Study Group: Machine perfusion or cold storage in deceased-donor kidney transplantation. N Engl J Med 366: $770-771,2012$.
10. Zhang Y, Fu Z, Zhong Z, Wang R, Hu L, Xiong Y, Wang Y and Ye Q: Hypothermic machine perfusion decreases renal cell apoptosis during ischemia/reperfusion injury via the Ezrin/AKT pathway. Artif Organs 40: 129-135, 2016.

11. Schold JD, Kaplan B, Howard RJ, Reed AI, Foley DP and Meier-Kriesche HU: Are we frozen in time? Analysis of the utilization and efficacy of pulsatile perfusion in renal transplantation. Am J Transplant 5: 1681-1688, 2005.

12. Eddy AA: Progression in chronic kidney disease. Adv Chronic Kidney Dis 12: 353-365, 2005.

13. Akcay A, Nguyen Q and Edelstein CL: Mediators of inflammation in acute kidney injury. Mediators Inflamm 2009: 137072, 2009.

14. Kono H, Nakagawa K, Morita S, Shinoda K, Mizuno R, Kikuchi E, Miyajima A, Umezawa K and Oya M: Effect of a novel nuclear factor- $\kappa \mathrm{B}$ activation inhibitor on renal ischemia-reperfusion injury. Transplantation 96: 863-870, 2013.

15. Latanich CA and Toledo-Pereyra LH: Searching for NF-kappaB-based treatments of ischemia reperfusion injury. J Invest Surg 22: 301-315, 2009.

16. Cao CC, Ding XQ, Ou ZL, Liu CF, Li P, Wang L and Zhu CF: In vivo transfection of NF-kappaB decoy oligodeoxynucleotides attenuate renal ischemia/reperfusion injury in rats. Kidney Int 65: 834-845, 2004.

17. Hatada EN, Krappmann D and Scheidereit C: NF-kappaB and the innate immune response. Curr Opin Immunol 12: 52-58, 2000.

18. Daemen MA, van't Veer C, Denecker G, Heemskerk VH, Wolfs TG, Clauss M, Vandenabeele P and Buurman WA: Inhibition of apoptosis induced by ischemia-reperfusion prevents inflammation. J Clin Invest 104: 541-549, 1999.

19. Linkermann A and Green DR: Necroptosis. N Engl J Med 370: 455-465, 2014.

20. Kaushal GP, Basnakian AG and Shah SV: Apoptotic pathways in ischemic acute renal failure. Kidney Int 66: 500-506, 2004.

21. Kaushal GP, Kaushal V, Hong X and Shah SV: Role and regulation of activation of caspases in cisplatin-induced injury to renal tubular epithelial cells. Kidney Int 60: 1726-1736, 2001

22. Lau A, Wang S, Jiang J, Haig A, Pavlosky A, Linkermann A, Zhang ZX and Jevnikar AM: RIPK3-mediated necroptosis promotes donor kidney inflammatory injury and reduces allograft survival. Am J Transplant 13: 2805-2818, 2013.

23. Opipari AW Jr, Boguski MS and Dixit VM: The A20 cDNA induced by tumor necrosis factor alpha encodes a novel type of zinc finger protein. J Biol Chem 265: 14705-14708, 1990.

24. Lee EG, Boone DL, Chai S, Libby SL, Chien M, Lodolce JP and Ma A: Failure to regulate TNF-induced NF-kappaB and cell death responses in A20-deficient mice. Science 289: 2350-2354, 2000.

25. Boone DL, Turer EE, Lee EG, Ahmad RC, Wheeler MT, Tsui C, Hurley P, Chien M, Chai S, Hitotsumatsu O, et al: The ubiquitin-modifying enzyme A20 is required for termination of Toll-like receptor responses. Nat Immunol 5: 1052-1060, 2004.

26. Catrysse L, Vereecke L, Beyaert R and van Loo G: A20 in inflammation and autoimmunity. Trends Immunol 35: 22-31, 2014.

27. Ma A and Malynn BA: A20: Linking a complex regulator of ubiquitylation to immunity and human disease. Nat Rev Immunol 12: 774-785, 2012.

28. Daniel S, Arvelo MB, Patel VI, Longo CR, Shrikhande G, Shukri T, Mahiou J, Sun DW, Mottley C, Grey ST and Ferran C: A20 protects endothelial cells from TNF-, Fas-, and NK-mediated cell death by inhibiting caspase 8 activation. Blood 104: 2376-2384, 2004.

29. Kunter U, Daniel S, Arvelo MB, Choi J, Shukri T, Patel VI, Longo CR, Scali ST, Shrikhande G, Rocha E, et al: Combined expression of A1 and A20 achieves optimal protection of renal proximal tubular epithelial cells. Kidney Int 68: 1520-1532, 2005.

30. Grey ST, Longo C, Shukri T, Patel VI, Csizmadia E, Daniel S, Arvelo MB, Tchipashvili V and Ferran C: Genetic engineering of a suboptimal islet graft with A20 preserves beta cell mass and function. J Immunol 170: 6250-6256, 2003.

31. Coornaert B, Carpentier I and Beyaert R: A20: Central gatekeeper in inflammation and immunity. J Biol Chem 284: 8217-8221, 2009.

32. Onizawa M, Oshima S, Schulze-Topphoff U, Oses-Prieto JA, Lu T, Tavares R, Prodhomme T, Duong B, Whang MI, Advincula $\mathrm{R}$, et al: The ubiquitin-modifying enzyme A20 restricts ubiquitination of the kinase RIPK 3 and protects cells from necroptosis. Nat Immunol 16: 618-627, 2015.

33. Bodonyi-Kovacs G, Strom TB and Putheti P: A20 - a biomarker of allograft outcome: a showcase in kidney transplantation. Adv Exp Med Biol 809: 103-116, 2014. 
34. Coornaert B, Baens M, Heyninck K, Bekaert T, Haegman M, Staal J, Sun L, Chen ZJ, Marynen P and Beyaert R: T cell antigen receptor stimulation induces MALT1 paracaspase-mediated cleavage of the NF-kappaB inhibitor A20. Nat Immunol 9: 263-271, 2008

35. De Smaele E, Zazzeroni F, Papa S, Nguyen DU, Jin R, Jones J, Cong R and Franzoso G: Induction of gadd45beta by NF-kappaB downregulates pro-apoptotic JNK signalling. Nature 414: 308-313, 2001

36. Tang G, Minemoto Y, Dibling B, Purcell NH, Li Z, Karin M and Lin A: Inhibition of JNK activation through NF-kappaB target genes. Nature 414: 313-317, 2001.

37. Chang L, Kamata H, Solinas G, Luo JL, Maeda S, Venuprasad K, Liu YC and Karin M: The E3 ubiquitin ligase itch couples JNK activation to TNFalpha-induced cell death by inducing c-FLIP(L) turnover. Cell 124: 601-613, 2006.

38. Vanden Berghe T, Grootjans S, Goossens V, Dondelinger Y, Krysko DV, Takahashi N and Vandenabeele P: Determination of apoptotic and necrotic cell death in vitro and in vivo. Methods 61 : 117-129, 2013.

39. Barba J, Zudaire JJ, Robles JE, Rosell D, Berian JM and Pascual I: Complications of kidney transplantation with grafts from expanded criteria donors. World J Urol 31: 893-900, 2013.

40. McLaren AJ, Jassem W, Gray DW, Fuggle SV, Welsh KI and Morris PJ: Delayed graft function: risk factors and the relative effects of early function and acute rejection on long-term survival in cadaveric renal transplantation. Clin Transplant 13: 266-272, 1999.

41. Padanilam BJ: Cell death induced by acute renal injury: a perspective on the contributions of apoptosis and necrosis. Am J Physiol Renal Physiol 284: F608-F627, 2003.

42. Bonegio R and Lieberthal W: Role of apoptosis in the pathogenesis of acute renal failure. Curr Opin Nephrol Hypertens 11: 301-308, 2002.

43. Bonventre JV and Zuk A: Ischemic acute renal failure: an inflammatory disease? Kidney Int 66: 480-485, 2004.

44. Linkermann A, Bräsen JH, Himmerkus N, Liu S, Huber TB Kunzendorf U and Krautwald S: Rip1 (receptor-interacting protein kinase 1) mediates necroptosis and contributes to renal ischemia/reperfusion injury. Kidney Int 81: 751-761, 2012.

45. Toronyi E: Role of apoptosis in the kidney after reperfusion. Orv Hetil 149: 305-315, 2008 (In Hungarian).

46. da Silva CG, Maccariello ER, Wilson SW, Putheti P, Daniel S, Damrauer SM, Peterson CR, Siracuse JJ, Kaczmarek E and Ferran C: Hepatocyte growth factor preferentially activates the anti-inflammatory arm of NF- $\mathrm{BB}$ signaling to induce A20 and protect renal proximal tubular epithelial cells from inflammation. J Cell Physiol 227: 1382-1390, 2012.

47. Rius J, Guma M, Schachtrup C, Akassoglou K, Zinkernagel AS, Nizet V, Johnson RS, Haddad GG and Karin M: NF-kappaB links innate immunity to the hypoxic response through transcriptional regulation of HIF-1alpha. Nature 453: 807-811, 2008.

48. Li C and Jackson RM: Reactive species mechanisms of cellular hypoxia-reoxygenation injury. Am J Physiol Cell Physiol 282: C227-C241, 2002.

49. Grey ST, Arvelo MB, Hasenkamp W, Bach FH and Ferran C: A20 inhibits cytokine-induced apoptosis and nuclear factor kappaB-dependent gene activation in islets. J Exp Med 190: 1135-1146, 1999
50. Arvelo MB, Cooper JT, Longo C, Daniel S, Grey ST, Mahiou J, Czismadia E, Abu-Jawdeh G and Ferran C: A20 protects mice from D-galactosamine/lipopolysaccharide acute toxic lethal hepatitis. Hepatology 35: 535-543, 2002.

51. Lutz J, Luong A, Strobl M, Deng M, Huang H, Anton M, Zakkar M, Enesa K, Chaudhury H, Haskard DO, et al: The A20 gene protects kidneys from ischaemia/reperfusion injury by suppressing pro-inflammatory activation. J Mol Med Berl 86: 1329-1339, 2008

52. Opipari AW Jr, Hu HM, Yabkowitz R and Dixit VM: The A20 zinc finger protein protects cells from tumor necrosis factor cytotoxicity. J Biol Chem 267: 12424-12427, 1992.

53. Hess S, Gottfried E, Smola H, Grunwald U, Schuchmann M and Engelmann H: CD40 induces resistance to TNF-mediated apoptosis in a fibroblast cell line. Eur J Immunol 28: 3594-3604, 1998.

54. Heyninck K, Denecker G, De Valck D, Fiers W and Beyaert R: Inhibition of tumor necrosis factor-induced necrotic cell death by the zinc finger protein A20. Anticancer Res 19: 2863-2868, 1999.

55. Lademann U, Kallunki T and Jäättelä $M: A 20$ zinc finger protein inhibits TNF-induced apoptosis and stress response early in the signaling cascades and independently of binding to TRAF2 or 14-3-3 proteins. Cell Death Differ 8: 265-272, 2001.

56. Du C, Guan Q, Yin Z, Zhong R and Jevnikar AM: IL-2-mediated apoptosis of kidney tubular epithelial cells is regulated by the caspase-8 inhibitor c-FLIP. Kidney Int 67: 1397-1409, 2005.

57. Du C, Wang S, Diao H, Guan Q, Zhong R and Jevnikar AM: Increasing resistance of tubular epithelial cells to apoptosis by shRNA therapy ameliorates renal ischemia-reperfusion injury. Am J Transplant 6: 2256-2267, 2006.

58. Won M, Park KA, Byun HS, Sohn KC, Kim YR, Jeon J, Hong JH, Park J, Seok JH, Kim JM, et al: Novel anti-apoptotic mechanism of A20 through targeting ASK1 to suppress TNF-induced JNK activation. Cell Death Differ 17: 1830-1841, 2010.

59. Nagamachi A, Nakata Y, Ueda T, Yamasaki N, Ebihara Y, Tsuji K, Honda Z, Takubo K, Suda T, Oda H, et al: Acquired deficiency of A20 results in rapid apoptosis, systemic inflammation, and abnormal hematopoietic stem cell function. PLoS One 9: e87425, 2014.

60. Zamzami N and Kroemer G: The mitochondrion in apoptosis: how Pandora's box opens. Nat Rev Mol Cell Biol 2: 67-71, 2001.

61. Cho BB and Toledo-Pereyra LH: Caspase-independent programmed cell death following ischemic stroke. J Invest Surg 21: 141-147, 2008.

62. Peltz M, He TT, Adams GA IV, Koshy S, Burgess SC, Chao RY, Meyer DM and Jessen ME: Perfusion preservation maintains myocardial ATP levels and reduces apoptosis in an ex vivo rat heart transplantation model. Surgery 138: 795-805, 2005.

63. Galluzzi L, Vitale I, Abrams JM, Alnemri ES, Baehrecke EH, Blagosklonny MV, Dawson TM, Dawson VL, El-Deiry WS, Fulda S, et al: Molecular definitions of cell death subroutines: Recommendations of the Nomenclature Committee on Cell Death 2012. Cell Death Differ 19: 107-120, 2012

64. Chan FK: Fueling the flames: mammalian programmed necrosis in inflammatory diseases. Cold Spring Harb Perspect Biol 4: a008805, 2012

65. Kaczmarek A, Vandenabeele P and Krysko DV: Necroptosis: the release of damage-associated molecular patterns and its physiological relevance. Immunity 38: 209-223, 2013. 